\title{
QUEEN'S
UNIVERSITY
BELFAST
}

\section{Atmospheric pressure microplasma for antibacterial silver nanoparticle/chitosan nanocomposites with tailored properties}

\author{
Sun, D., Turner, J., Jiang, N., Zhu, S., Zhang, L., Falzon, B., McCoy, C., Maguire, P., Mariotti, D., \& Sun, D. \\ (2020). Atmospheric pressure microplasma for antibacterial silver nanoparticle/chitosan nanocomposites with \\ tailored properties. Composites Science and Technology. https://doi.org/10.1016/j.compscitech.2019.107911
}

Published in:

Composites Science and Technology

Document Version:

Peer reviewed version

Queen's University Belfast - Research Portal:

Link to publication record in Queen's University Belfast Research Portal

\section{Publisher rights}

Copyright 2019 Elsevier.

This manuscript is distributed under a Creative Commons Attribution-NonCommercial-NoDerivs License

(https://creativecommons.org/licenses/by-nc-nd/4.0/), which permits distribution and reproduction for non-commercial purposes, provided the author and source are cited.

\section{General rights}

Copyright for the publications made accessible via the Queen's University Belfast Research Portal is retained by the author(s) and / or other copyright owners and it is a condition of accessing these publications that users recognise and abide by the legal requirements associated with these rights.

Take down policy

The Research Portal is Queen's institutional repository that provides access to Queen's research output. Every effort has been made to ensure that content in the Research Portal does not infringe any person's rights, or applicable UK laws. If you discover content in the Research Portal that you believe breaches copyright or violates any law, please contact openaccess@qub.ac.uk. 


\title{
Atmospheric pressure microplasma for antibacterial silver nanoparticle/chitosan nanocomposites with tailored properties
}

\author{
Daye Sun ${ }^{1}$, Jonathan Turner ${ }^{2}$, Nan Jiang ${ }^{3}$, Songsong Zhu ${ }^{3}$, Li Zhang ${ }^{4}$, Brian G. \\ Falzon ${ }^{1}$, Colin P. McCoy ${ }^{2}$, Paul Maguire ${ }^{5}$, Davide Mariotti ${ }^{5}$, Dan Sun $^{1, *}$ \\ ${ }^{1}$ Advanced Composites Research Group, School of Mechanical and Aerospace Engineering, \\ Ashby Building, Stranmillis Road, Queen's University Belfast, Belfast, BT9 5AH, UK. \\ ${ }^{2}$ School of Pharmacy, Queen's University Belfast, Belfast BT9 7BL, UK \\ ${ }^{3}$ State Key Laboratory of Oral Diseases, \& National Clinical Research Center for Oral \\ Disease, \& West China Hospital of Stomatology, Sichuan University, Chengdu 610041, \\ China \\ ${ }^{4}$ Research Centre for Nano-Biomaterials, Analytical \& Testing Center, Sichuan University, \\ Chengdu 610065, China \\ ${ }^{5}$ Nanotechnology and Integrated Bioengineering Center (NIBEC), Ulster University, Co \\ Antrim BT37 OQB, UK \\ *Corresponding author: d.sun@qub.ac.uk
}




\begin{abstract}
Room temperature atmospheric pressure microplasma (APM) was deployed for the first time for the in situ synthesis of anti-bacterial silver nanoparticle/chitosan (AgNP/CS) nanocomposites. The plasma induced liquid chemistry plays a role in the in situ formation of AgNP, the size distribution of which depends on the silver salt precursor concentration. The microplasma process has also simultaneously tailored the physical properties of the composites, through molecular chain scission and formation of physically crosslinked polymer network. The formation of AgNP within the in situ modified chitosan has led to nanocomposites with overall improved mechanical properties and better stability in simulated body fluid. Our plasma synthesized AgNP/CS nanocomposites also demonstrate effective antibacterial properties against $E$. coli and $S$. aureus bacterial strains, showing their promise in potential antimicrobial applications.
\end{abstract}

Keywords: E. Atmospheric pressure microplasma; A. Silver nanoparticle; A. Chitosan; A. Nanocomposites; B. Antibacterial 


\section{Introduction}

Antimicrobial resistance (AMR) presents a huge threat to the global health and economy and there is an urgent need to develop antibiotic alternatives to combat AMR [1]. Nanoparticles, in particular, silver nanoparticles (AgNPs) are promising for tackling this challenge due to their highly effective antibacterial properties against a wide range of grampositive and gram-negative bacteria strains [2-4]. When interacting with bacterial cells, AgNPs can either lead to the formation of reactive oxygen species (ROS) or the release of silver ions $\left(\mathrm{Ag}^{+}\right)$, contributing to a wide spectrum of antibacterial activities via multiple reaction pathways [3]. Despite their promising applications, the health risk associated with the use of free NPs may be a concern for their impacts on healthy cells and host tissues [5]. To minimize the uncontrolled release of AgNPs and for localized treatment / enhanced treatment efficacy, polymer based nanocomposites incorporating AgNPs have been developed as an alternative solution for certain antimicrobial applications such as air filtration [4], tissue scaffolds [6], implant coating [7], and wound dressings [8].

The commonly used preparation methods for $\mathrm{AgNP} /$ polymer nanocomposites include physical mixing of pre-synthesized AgNPs with polymer solution and in situ chemical reduction of $\mathrm{AgNO}_{3}$ in polymer solutions $[8,9]$. Other non-wet chemistry based synthesis approaches such as $\gamma$-irradiation [10], microwave [11], and thermal [12] irradiations have also been explored. Unfortunately, most of these methods would require long processing time (hours), complicated multi-step synthesis process, and/or the use of potentially hazardous chemicals /irradiation.

Non-thermal plasmas (NTP) such as dielectric barrier discharges (DBD) and corona discharges, can operate under near room temperature and is an alternative approach for the surface treatment and/or synthesis of a wide range of materials. Several researchers have deployed NTPs to produce antibacterial AgNP/polymer nanocomposites [13]. For instance, $\mathrm{Vu}$ et al. prepared AgNP/polyamide (PA) composites by immersing DBD activated PA into preformed AgNP colloid to achieve enhanced AgNP grafting on the polymer surface $[14,15]$. Other researchers deployed NTPs for in situ plasma polymerization (such as hydrocarbon based polymers [16-18], polyaniline [19], diethylglycol-dimethyl-ether (DEGME) [20], and polyethyleneoxide (PEO) [21], where AgNPs were sputtered simultaneously into the polymer matrices during their formation. Although the above mentioned NTP techniques benefit from reduced use of chemicals, faster fabrication, and easier application to various substrates, the technique was primarily constrained to surface treatment/in situ polymerization. 
In recent years, the use of room temperature atmospheric pressure microplasma (APM), in particular APM/ liquid interaction has emerged as a new technique for the in situ synthesis of metal NPs or nanocomposites containing metal NPs [22]. The plasma induced liquid chemistry (PiLC) can produce various energetic/reactive species such as solvated electrons, radicals (e.g. $\mathrm{OH} \bullet, \mathrm{H} \bullet$, and $\mathrm{O} \bullet$ ), and $\mathrm{H}_{2} \mathrm{O}_{2}$ etc. at the plasma-liquid interface or inside the bulk liquid. These species could contribute to the reduction of metal cations, leading to formation of various metal NPs such as AuNPs and AgNPs in aqueous solutions [23,24]. With the use of PiLC, we have successfully synthesized a wide range of nanocomposites containing metal based NPs, such as AuNP/CNT [25], AuNP/GO [26], $\mathrm{Fe}_{3} \mathrm{O}_{4} / \mathrm{PINIAM} \mathrm{[27],} \mathrm{AuNP/PEDOT:PSS} \mathrm{[28],} \mathrm{and} \mathrm{PVA}$ hydrogel composites containing AuNP, AgNP or AuAg alloyed NPs [29]. One of the unique features of the PiLC synthetic approach is its ability to create highly charged NP surfaces within minutes, resulting in highly dispersed / stable NPs without the need for reductants, surfactants or ligand chemistry. The plasma synthesized composites can be further processed into different forms such as gels, sponges, coatings and films for further applications.

Chitosan (CS) is a biocompatible and biodegradable natural polymer, commonly used in the biomedical field [30-33]. By incorporating AgNPs into CS, one can obtain anti-microbial nanocomposites that can be used for a wide range of applications such as wound dressings, tissue engineering, drug delivery and water treatment, etc [34-36]. In the present work, a direct current (DC) atmospheric pressure microplasma has been deployed for the in situ synthesis of AgNP/CS nanocomposites. The resulting AgNP/CS nanocomposites were further processed into films, and their antibacterial activities were tested against E. coli and S. aureus bacterial strains.

\section{Methods}

\subsection{Materials}

Chitosan (CS, deacetylation > 92.6\%) was purchased from Heppe Medical Chitosan GmbH company. Acetic acid (100\%, AnalaR NORMAPUR ${ }^{\circledR}$ ACS, Reag. Ph. Eur. Analytical Reagent) was supplied by VWR. Silver nitrate (99.9999\% trace metals basis) was purchased from Sigma-Aldrich. Escherichia coli (E. coli, ATCC 11303) and Staphylococcus aureus (S. aureus, ATCC 6538) used for antibacterial investigation were received from LGC Standards, Middlesex, UK. E. coli and S.aureus were grown in Mueller-Hinton broth (MHB), obtained from Oxoid Ltd, Hampshire, UK. Phosphate buffered saline (PBS), nutrient agar (NA) plates and Mueller-Hinton agar (MHA) plates were obtained from Oxoid Ltd, Hampshire, UK.

\subsection{APM experiment}


$2 \mathrm{wt} \%$ CS solution was prepared by dissolving appropriate amount of as-purchased CS powder in $2 \%(\mathrm{v} / \mathrm{v})$ acetic acid aqueous solution under room temperature for $24 \mathrm{~h}$. Appropriate amount of $\mathrm{AgNO}_{3}$ solution $(10 \mathrm{mM})$ was introduced into the $\mathrm{CS} /$ acetic acid aqueous solutions to obtain $\mathrm{AgNO}_{3} / \mathrm{CS}$ mixtures with $1 \% \mathrm{CS}$ and different $\mathrm{AgNO}_{3}$ concentrations $(1,2$, and $4 \mathrm{mM}$, respectively). After 30 min stirring, the $\mathrm{AgNO}_{3} / \mathrm{CS}$ mixtures were subjected to plasma treatment.

Scheme 1 shows the plasma set-up in the present work. The anode (carbon rod) was immersed into the $\mathrm{AgNO}_{3} / \mathrm{CS}$ aqueous mixtures, while the cathode (stainless steel capillary with inner diameter of $250 \mu \mathrm{m}$ ) was positioned approximately $2 \mathrm{~mm}$ above the mixture surface. Helium $(\mathrm{He})$ gas (flow rate $=25 \mathrm{sccm}$ ) was supplied through the capillary and the plasma can be ignited at the gas / liquid interface at a voltage of $\sim 4 \mathrm{kV}$. Once the plasma was ignited, the voltage dropped to $\sim 2.8 \mathrm{kV}$. The current was then adjusted and maintained at $5 \mathrm{~mA}$ to sustain the plasma and the $\mathrm{AgNO}_{3} / \mathrm{CS}$ solutions were gently stirred using magnetic stirrer throughout the treatment $(10 \mathrm{~min})$. The plasma treated samples were named as 1, 2, and $4 \mathrm{mM} \mathrm{AgNP/CS}$, respectively, according to the initial concentration of the $\mathrm{AgNO}_{3}$ used. For comparison, pure CS (1\%) solution was also treated by plasma under the same condition.

\subsection{Characterization}

Ultraviolet-visible (UV-vis) spectra of all samples were recorded by a Cary $60 \mathrm{UV}-\mathrm{Vis}$ Spectrometer (Agilent Technologies). Diluted (10x) liquid AgNP/CS samples were dropcasted / dried in dark on TEM sample grids (Agar Scientific), to study the size and morphology of AgNPs within the nanocomposites using transmission electron microscope (TEM, Tecnai G2 F20 S-TWIN, FEI, USA). Based on the TEM images, AgNPs size distributions were analysed using "FUJI" software, where over 300 NPs were selected for each sample. The particle size was evaluated automatically using the "Particle Size" function within the software. X-ray photoelectron spectroscopy (XPS) of AgNP/CS nanocomposites were conducted using

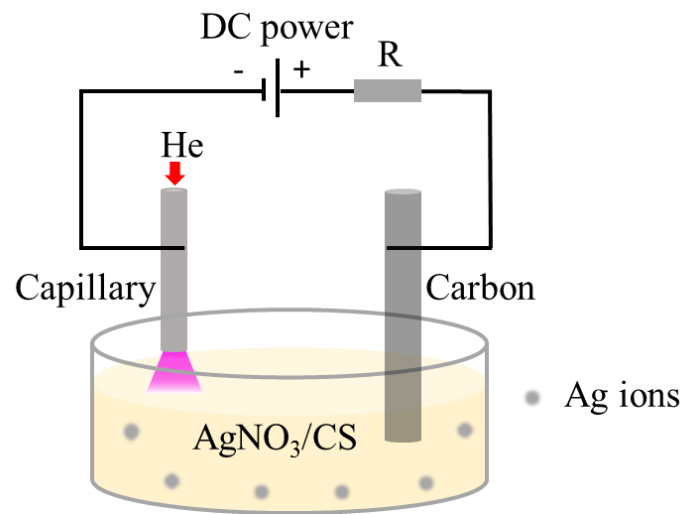

Scheme 1. Diagram of plasma set-up used in this work. 
a Kratos Axis Ultra XPS system and the results were analysed by an open source software CasaXPS. Samples for XPS were prepared by drop casting liquid AgNP/CS solutions onto intrinsic silicon wafer, followed by drying under ambient condition.

\subsection{Preparation and characterization of AgNP/CS composite films}

The 1, 2, $4 \mathrm{mM} \mathrm{AgNP/CS}$ composite films were prepared by casting $9 \mathrm{ml}$ of each plasma treated sample onto a $5 \mathrm{~cm} \times 9 \mathrm{~cm}$ glass slide. The samples were then oven dried at $60{ }^{\circ} \mathrm{C}$ for $6 \mathrm{~h}$ (no further weight loss). Control film samples (pure CS and plasma treated CS) were also prepared for comparison. The thickness of the all film samples was $0.02 \pm 0.002 \mathrm{~mm}$.

Fourier transform infrared (FTIR) of all films were conducted under ambient condition using Perkin Elmer Spectrum 100 FT-IR Spectrometer (equipped with a Universal Attenuated Total Reflectance (ATR) sampling accessory). Differential Scanning Calorimetry (DSC) analysis was carried in a $\mathrm{N}_{2}$ atmosphere at a heating rate of $10{ }^{\circ} \mathrm{C} \min ^{-1}$ using a Perkin-Elmer DSC 6 instrument to examine the thermodynamic characteristics of the films. Thermogravimetric analysis (TGA) was carried out using a TA Instruments SDT-Q600 in a $\mathrm{N}_{2}$ environment with scan range of 50 to $800{ }^{\circ} \mathrm{C}$ at a heating rate of $10{ }^{\circ} \mathrm{C} \mathrm{min}{ }^{-1}$.

\subsection{Swelling ratio}

The swelling ratio of the samples were tested using the gravimetric method following established procedure [37]. The film of each sample was cut into triplicate pieces using pinpunch set. After initial weighing of the dried film $\left(\mathrm{W}_{\mathrm{d}}\right)$, all film samples were immersed in simulated body fluid (10 $\mathrm{ml} \mathrm{PBS,} \mathrm{PH}=7.4)$ at $37^{\circ} \mathrm{C}$. After $24 \mathrm{~h}$, the films were taken out and the excess water were removed using filter paper. The swelling ratio of each film sample can be calculated according to the following equation:

$$
\text { Swelling ratio }(\%)=\left[\left(\mathrm{W}_{\mathrm{s}}-\mathrm{W}_{\mathrm{d}}\right) / \mathrm{W}_{\mathrm{d}}\right] \times 100
$$

where the $\mathrm{W}_{\mathrm{s}}$ and $\mathrm{W}_{\mathrm{d}}$ are the weight of swollen film and dry film, respectively.

\subsection{Mechanical tests}

The tensile tests of all film samples were measured using a Lloyds LRX series materials testing machine $(50 \mathrm{~N})$ at a speed of $2 \mathrm{~mm} \mathrm{~min}^{-1}$ following ASTMD882-01 [38]. Films were cut into dumb-bell coupons with gauge length of $25 \mathrm{~mm}$ and gauge width of $4 \mathrm{~mm}$ using a Ray-Ran test machine cutter. Stress-strain curves of each sample, and the corresponding tensile strength $(\mathrm{MPa})$ and Young modulus (MPa) were all recorded by the machine. Five measurements were repeated for each group and the mean value was taken for further analysis.

\subsection{Antibacterial tests}

The antibacterial activities of all the films were evaluated against gram-negative E. coli and gram-positive S. aureus strains using the CLSI method [39]. The bacterial strains were cultured 
in MHB for $24 \mathrm{~h}$ in a $37^{\circ} \mathrm{C}$ orbital incubator to obtain bacterial pellets. The as-obtained pellets were re-suspended in PBS to an optical density ( $\left.\mathrm{OD}_{550}\right)$ value of 0.3 at $550 \mathrm{~nm}$, corresponding to an approximately $1 \times 10^{8} \mathrm{cfu} \mathrm{mL}^{-1}$ inoculum. The bacteria suspensions were spread evenly onto NA plates for E. coli and MHA plates for S. aureus using cotton swabs, after which $4 \mathrm{~mm}$ circular film samples were directly placed on the inoculated agar plates. After $24 \mathrm{~h}$ incubation under $37{ }^{\circ} \mathrm{C}$, the diameter of the incubation zones were measured to determine their antibacterial activity. Pure CS and plasma treated CS films were used as references, and five replicates were tested for each group.

\section{Result and discussions}

In contrast to the clear, colourless pure CS solution, plasma treatment led to immediate colour change in all samples, see Figure 1 inset. To further confirm the optical property of all samples, the test solutions were analysed using the UV-vis spectroscopy (see Figure 1). It can be seen that the plasma treatment had no significant influence on the absorption spectrum of CS, despite the slight colour change seen for the plasma treated CS sample. With increasing concentration of $\mathrm{AgNO}_{3}$ added into $\mathrm{CS}$, the plasma treated $\mathrm{AgNO}_{3} / \mathrm{CS}$ mixtures exhibit more distinctive colour change. This is accompanied by new characteristic peaks emerged at $412,420,425 \mathrm{~nm}$ for plasma treated 1,2,4 $\mathrm{mM} \mathrm{AgNO}_{3} / \mathrm{CS}$ mixtures, respectively, which coincide with the typical surface plasmon resonance (SPR) band of AgNPs[40]. The red shift of SPR peaks in the UV-Vis spectra is indicative of growing AgNP size within the plasma treated samples [40]. The morphologies and sizes of AgNPs formed within the plasma treated $\mathrm{AgNO}_{3} / \mathrm{CS}$ were further investigated by TEM. Figure 2a-c show some typical images, where the synthesized AgNPs (dark particles) are well-dispersed. Particle size distribution analysis (Figure 2d-f)

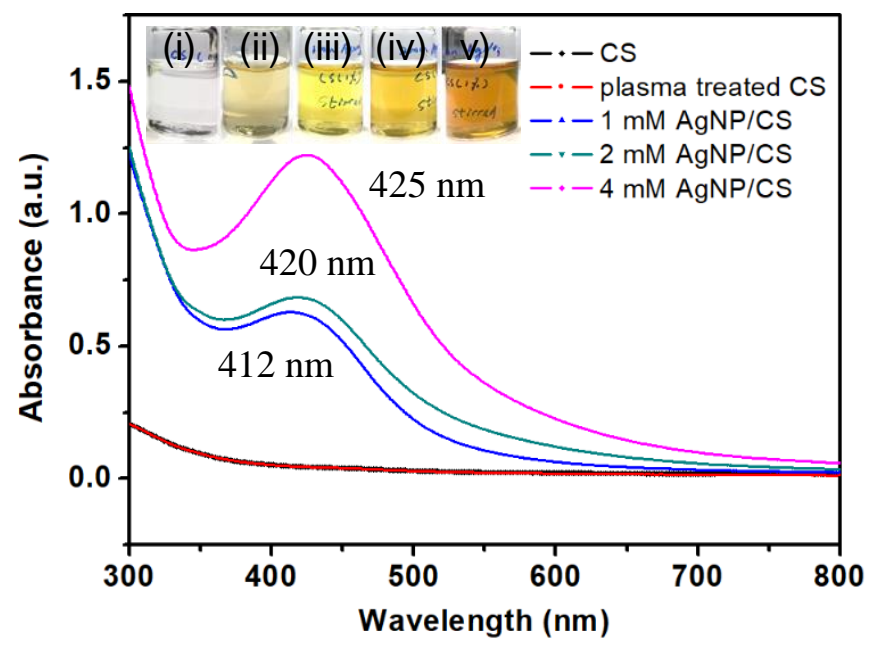

Figure 1. UV-vis spectra of pure CS and plasma treated CS, $1 \mathrm{mM}, 2 \mathrm{mM}$, and $4 \mathrm{mM}$ $\mathrm{AgNO}_{3} / \mathrm{CS}$ mixtures. Insets: images of (i) CS and (ii) - (v) plasma treated CS, $1 \mathrm{mM}, 2 \mathrm{mM}$, and $4 \mathrm{mM} \mathrm{AgNO} 3 / \mathrm{CS}$ mixtures, respectively. 


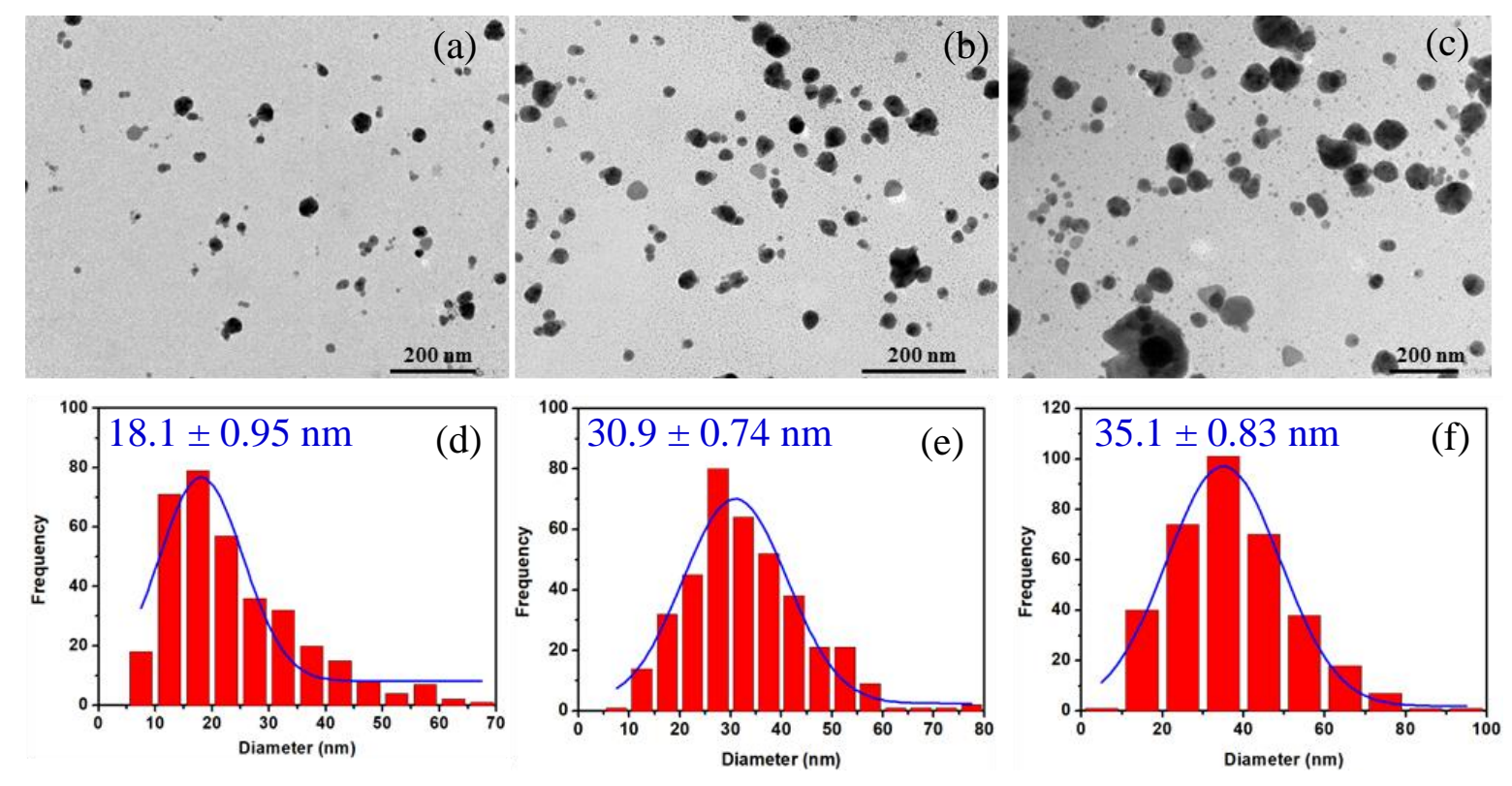

Figure 2. TEM images of (a) $1 \mathrm{mM}$, (b) $2 \mathrm{mM}$, and (c) $4 \mathrm{mM} \mathrm{AgNP/CS}$ nanocomposites, respectively. Corresponding size distribution of AgNPs within (d) $1 \mathrm{mM}$, (e) $2 \mathrm{mM}$, and (f) $4 \mathrm{mM}$ AgNP/CS nanocomposites, respectively.

suggests that the average $\mathrm{AgNPs}$ size increases with increasing initial $\mathrm{AgNO}_{3}$ precursor concentration, consistent with the red shift of the SPR peak found in the UV-vis analysis.

XPS analysis of plasma treated $\mathrm{AgNO}_{3} / \mathrm{CS}$ was carried out to confirm the atomic states of silver element. It is observed that the survey scans of the three Ag containing samples (Figure 3a) all present distinguished Ag peaks. The core Ag 3d peaks of each samples (Figure 3b-d) can be all well fitted into two doublet components, where the doublet centred at binding energy (BE) $\sim 367.9 / 374.0 \mathrm{eV}$ correlates to the atomic $\mathrm{Ag}^{0}$ state and the doublet centred at $\mathrm{BE} \sim 368.9 / 375.0$ $\mathrm{eV}$ correlates to the ionic $\mathrm{Ag}^{\delta+}$ state, respectively [41]. The detailed BE and atomic fraction of all fitted elements are listed in Table 1. The XPS results further confirm that the $\mathrm{Ag}^{+}$ion within the $\mathrm{AgNO}_{3} / \mathrm{CS}$ were mostly reduced into $\mathrm{Ag}^{0}$ state by plasma treatment.

As discussed earlier, the PiLC can generate various energetic/reactive species, which may participate in the multiphase interaction (that involves gas, $\mathrm{AgNO}_{3}, \mathrm{CS}$, and water) at the plasma/liquid interface. The AgNP formation triggered by PiLC has been investigated by several workers. Despite the various plasma sources used in different studies, it is commonly recognized that both the highly energetic solvated electrons (from the plasma phase) and $\mathrm{H}$ radicals (induced by plasma-liquid interaction) play a role in the AgNP reduction [24,42-44]. In addition, the ultraviolet (UV) irradiation can be produced in accompany of our plasma process [45,46], which is also likely to contribute to the AgNP formation [47].

The chemical structural properties of all samples were studied by FTIR, see Figure 4 . The broad bands around 3200 to $3500 \mathrm{~cm}^{-1}$ is attributed to the $-\mathrm{OH}$ and $-\mathrm{NH}_{2}$ groups stretching vibrations; 
(a)
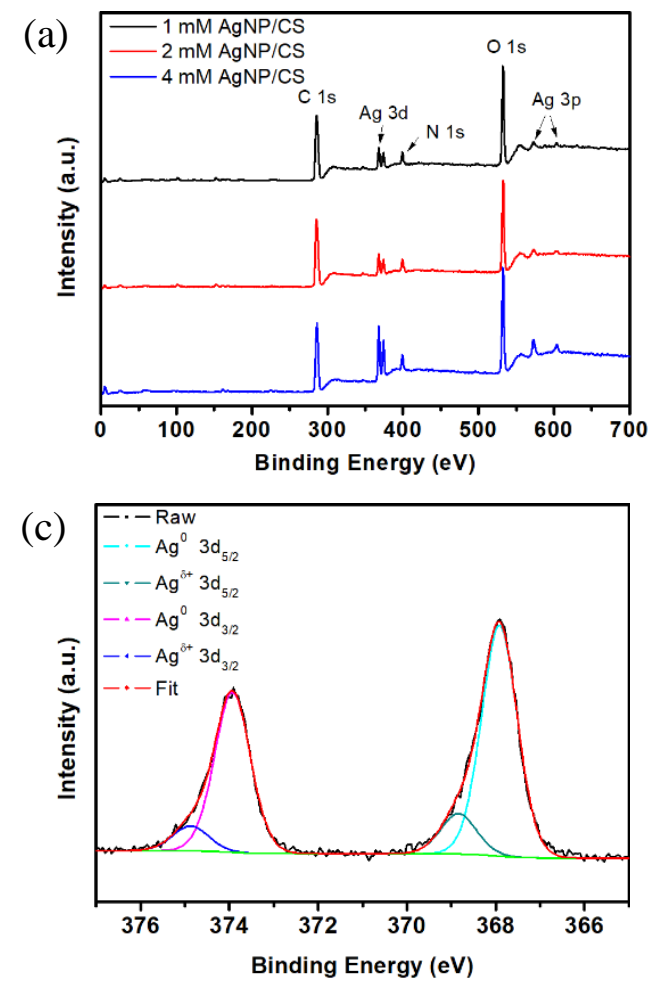

(b)

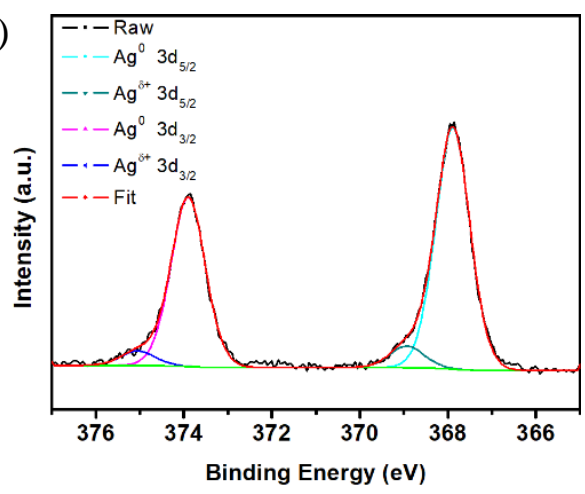

(d)

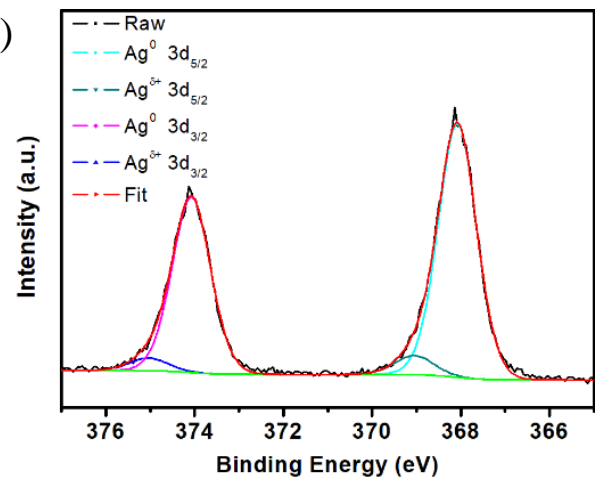

Figure 3. (a) Survey XPS spectra of $1 \mathrm{mM}, 2 \mathrm{mM}$, and $4 \mathrm{mM}$ AgNP/CS nanocomposites; (b)-(d) Ag 3d core XPS spectrum of $1 \mathrm{mM}, 2 \mathrm{mM}$, and $4 \mathrm{mM} \mathrm{AgNP/CS}$ nanocomposites, respectively.

the peaks at around $1560 \mathrm{~cm}^{-1}$ is the $\mathrm{NH}$ bending (amide II) $\left(\mathrm{NH}_{2}\right)$ peak; peaks at around 1647 $\mathrm{cm}^{-1}$ is due to the C-O stretching (amide I) of O-C-NHR; multiple peaks at around 2927, 2884, 1411, 1321 and $1260 \mathrm{~cm}^{-1}$ correspond to $\mathrm{CH}_{2}$ bending (within pyranose rings), $1078 \mathrm{~cm}^{-1}$ is for saccharide structures and the band at $1380 \mathrm{~cm}^{-1}$ is due to $\mathrm{CH}_{3}$ wagging [48]. It is noticed that, comparing to CS and plasma treated CS films, new peaks at 825 and $800 \mathrm{~cm}^{-1}$ emerged in the spectra of AgNP/CS films. This can be attributed to the plane vibration bands of N-H due to the interaction between AgNPs and CS [49,50].

The thermal properties of all film samples were analysed by DSC and TGA respectively and the results are shown in Figure 5. The DSC thermograms (Figure 5a) of all samples exhibit a broad endothermic peak ranging from 120 to $200{ }^{\circ} \mathrm{C}$, which are due to the dehydration process

Table 1. Ag 3d peak analysis results for 1, 2, and $4 \mathrm{mM} \mathrm{AgNP/CS}$ nanocomposites.

\begin{tabular}{|c|c|c|c|c|c|}
\hline \multirow{2}{*}{ Samples } & & \multicolumn{4}{|c|}{ Ag species } \\
\hline & & $\mathrm{Ag}^{0} 3 \mathrm{~d}_{5 / 2}$ & $A g^{\bar{D}+} 3 d_{5 / 2}$ & $\mathrm{Ag}^{0} 3 \mathrm{~d}_{3 / 2}$ & $\mathrm{Ag}^{\mathrm{\delta}+} 3 \mathrm{~d}_{3 / 2}$ \\
\hline \multirow{2}{*}{$1 \mathrm{mMAgNP} / \mathrm{CS}$} & $\mathrm{BE}(\mathrm{eV})$ & 367.9 & 368.9 & 373.9 & 375.0 \\
\hline & Fraction (\%) & 54.04 & 4.04 & 37.87 & 3.25 \\
\hline \multirow{2}{*}{$2 \mathrm{mM}$ AgNP/CS } & $\mathrm{BE}(\mathrm{eV})$ & 367.9 & 368.9 & 373.9 & 374.9 \\
\hline & Fraction (\%) & 50.61 & 8.84 & 35.08 & 5.46 \\
\hline \multirow{2}{*}{$4 \mathrm{mMAgNP} / \mathrm{CS}$} & $\mathrm{BE}(\mathrm{eV})$ & 368.1 & 369.0 & 374.1 & 375.0 \\
\hline & Fraction (\%) & 54.99 & 4.14 & 38.12 & 2.75 \\
\hline
\end{tabular}




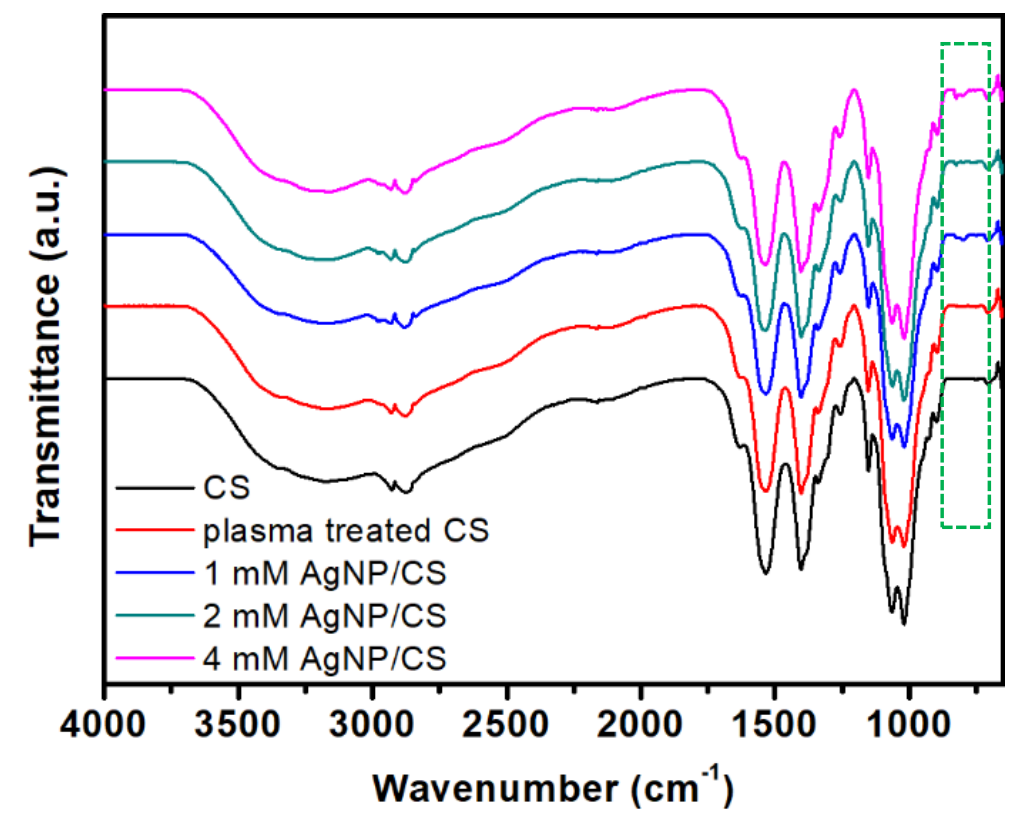

Figure 4. FTIR spectra of CS, plasma treated CS, $1 \mathrm{mM}, 2 \mathrm{mM}$, and $4 \mathrm{mM} \mathrm{AgNP/CS} \mathrm{films.}$

of water constrained in the sample via hydrogen bonds [51]. The exothermic peaks starting from $275^{\circ} \mathrm{C}$ within the DSC thermograms correspond to the decomposition process of the CS polymer chains [52]. The TGA (Figure 5b) graphs suggest the decomposition of all tested samples involves two stages. Stage I (100 to $\left.190^{\circ} \mathrm{C}\right)$ can be associated to the weight loss of water, and stage II is due to the decomposition of polysaccharide structures, which closely matches the DSC profiles. When the temperature reached $800{ }^{\circ} \mathrm{C}$, samples with higher initial $\mathrm{AgNO}_{3}$ concentration show less weight loss, indicating greater remnant of AgNPs.

The water uptake ability of CS and CS based nanocomposites is key to their biomedical applications [53]. The swelling behaviours of pure CS, plasma treated CS and AgNP/CS films were evaluated and their swelling ratios are demonstrated in Figure 6. It was observed that pure CS films dissolved completely in PBS solution after $24 \mathrm{~h}$ (See Figure S1, supporting
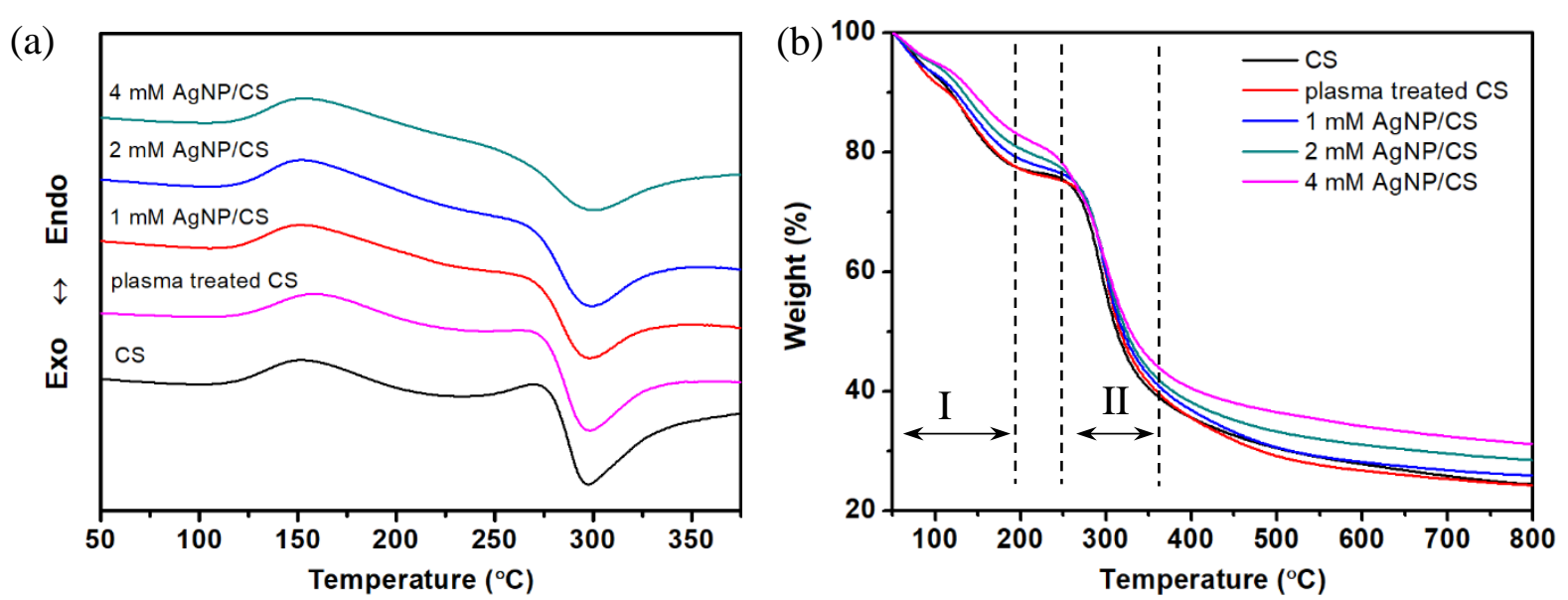

Figure 5. The (a) DSC and (b) TGA curves of CS, plasma treated CS, $1 \mathrm{mM}, 2 \mathrm{mM}$, and 4 $\mathrm{mM}$ AgNP/CS films. 


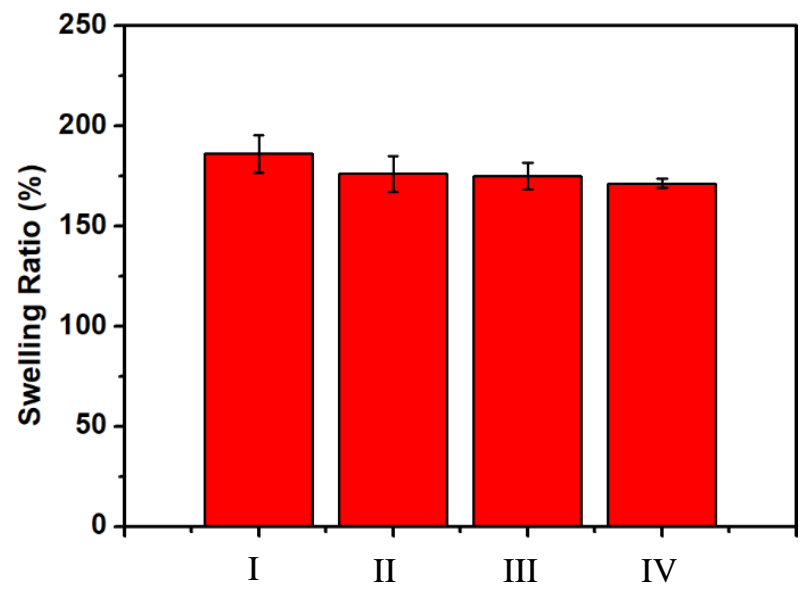

Figure 6. Swelling ratio of (I) plasma treated CS, (II) $1 \mathrm{mM}$, (III) $2 \mathrm{mM}$, and (IV) $4 \mathrm{mM}$ AgNP/CS films in PBS solution (PH=7.4), respectively.

information). In contrast, the plasma treated CS films remain stable in PBS and demonstrate a swelling ratio of $186.16 \pm 9.27 \%$. This can be explained by the formation of crosslinked structures in plasma treated CS [54]. As discussed earlier, PiLC can generate various energetic/reactive radicals, such as $\mathrm{OH} \bullet, \mathrm{H} \bullet$, and $\mathrm{O} \bullet$. It is widely accepted that $\mathrm{OH} \bullet$ can induce cleavage of the $\beta-1-4$ glycosidic linkages and the oxygenation of d-glucopyranose rings within CS chains, leading to effective CS chain scission (see Step I in Scheme 2) [55,56]. At the same time, this process can also lead to the formation of aldehyde groups, which can effectively crosslink with amino groups of CS fragments via hydrogen bonds [55]. As a result, the PiLC has altered the physical structures of CS, leading to a more robust crosslinked network consisting of shorter CS molecular chains (Step II in scheme 2). This has in turn enhanced the stability of CS and prevented its dissolution in PBS. Compared to plasma treated CS film, the swelling ratio of AgNP/CS films (also stable in PBS, see Figure S1 in supporting information) decreases with increasing initial $\mathrm{AgNO}_{3}$ concentration, see Figure 6. This may be due to the

Step I

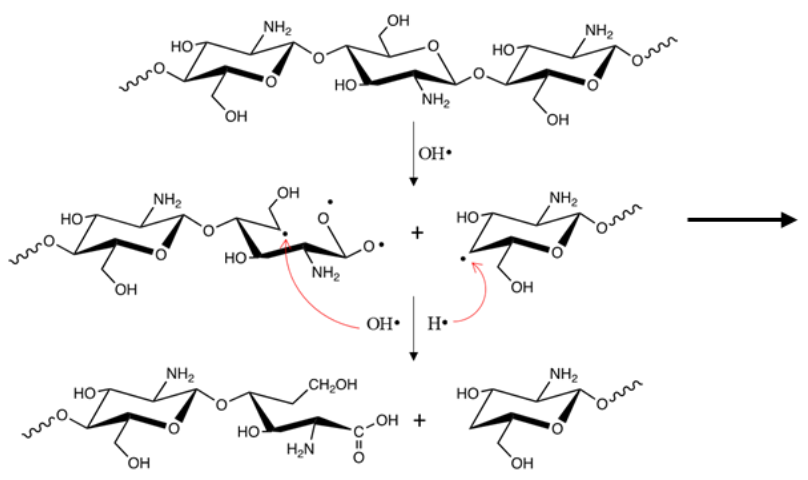

Step II

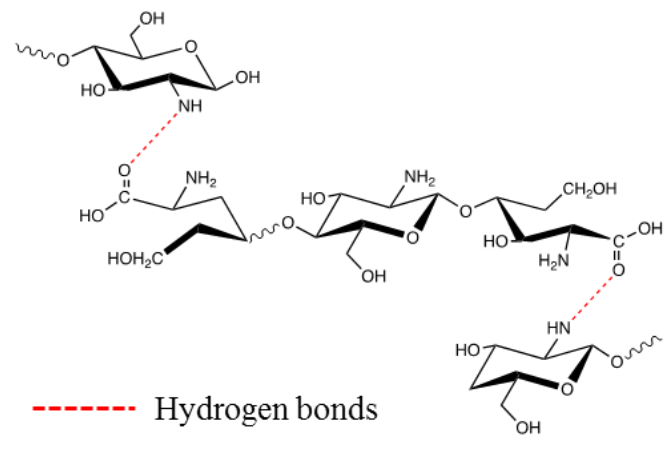

Scheme 2. Simplified scheme illustrating formation of crosslinked CS structures with shorter molecular chains induced by plasma chemistry. 
greater $\mathrm{AgNO}_{3}$ initial concentration has resulted in greater $\mathrm{AgNP}$ contents in the polymer network (as indicated by the TGA results), hence there is less room for holding water [57].

Figure 7 shows typical stress-strain curves of the composite film samples obtained from the tensile tests. Compared to pure CS, the tensile strength of plasma treated CS decreased, while the strain at break increased significantly. The tensile strength of polymers can be affected by both molecule weight and crosslinking [58]. It is widely accepted that reactive species generated by PiLC can lead to the scission of CS chains (see Scheme 2) and formation of crosslinked network between these shortened CS chains via hydrogen bonds [55,56]. It is worth noting that the hydrogen bonds based physical crosslinking is different from those covalent crosslinks seen in thermosetting materials. The hydrogen bonds can be mobile within the gel network under dynamic loading [59]. The mobility of hydrogen bonding and the presence of shorter CS molecular chains could be the reason for the greater elongation observed for the plasma treated CS films [60]. On the other hand, the shorter CS chains could be the reason for the decreased tensile strength of CS after the plasma treatment. Figure 8a and 8b shows that both tensile strength and Young's modulus of AgNP/CS are generally greater than those of plasma treated CS. The enhanced tensile strength can be attributed to the presence of AgNPs, which act as nanoreinforcement enhancing the mechanical properties (e.g., stiffness and tensile strength) of the composites through their interaction with the $\mathrm{CS}-\mathrm{NH}_{2}$ functions (see Figure 4 FTIR spectra) [37,61]. However, when AgNP content further increases, the nanoparticles may

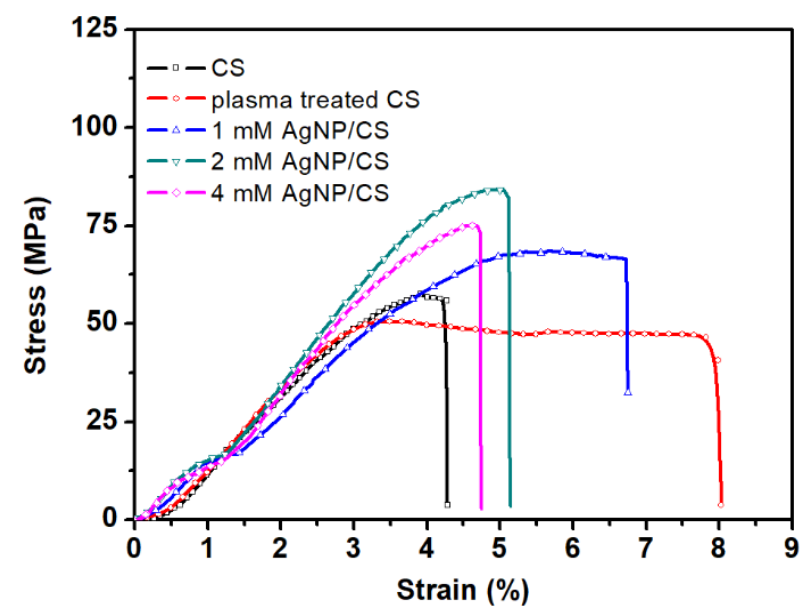

Figure 7. (a) The stress - strain curves of CS, plasma treated CS, $1 \mathrm{mM}, 2 \mathrm{mM}$, and $4 \mathrm{mM}$ AgNP/CS composite films. 

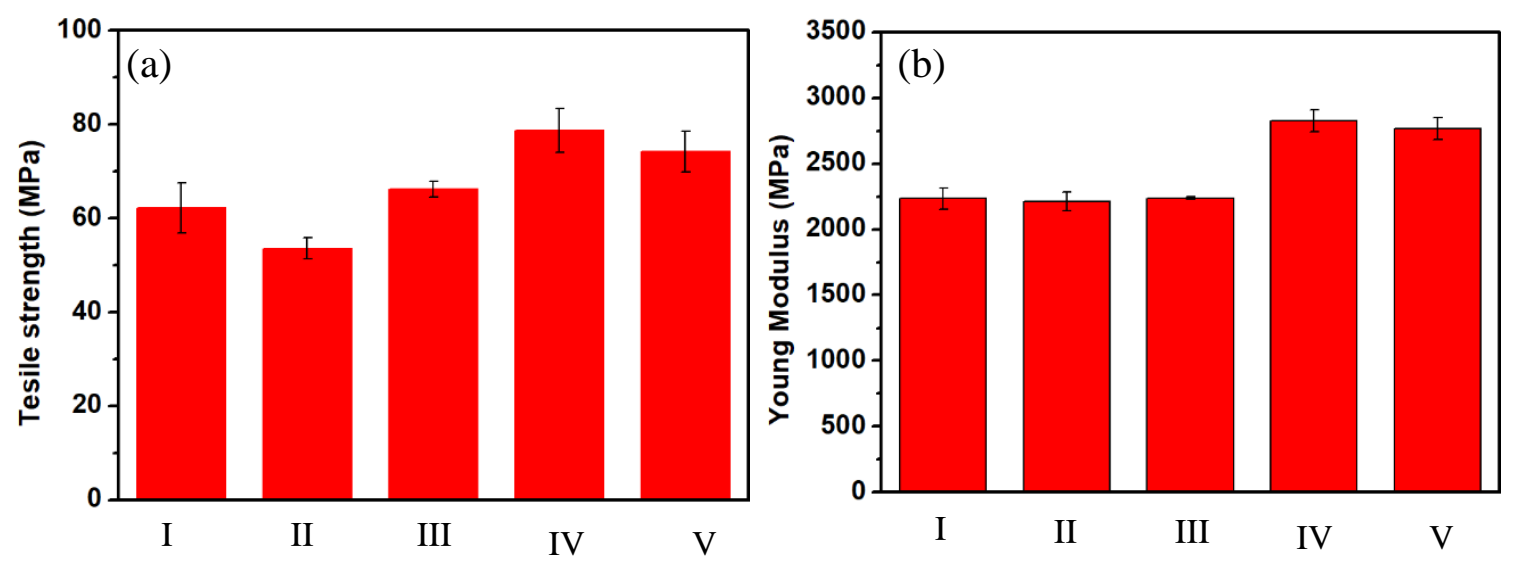

Figure 8. (a) Tensile strength-strain and (b) Young modulus of (I) CS, (II) plasma treated CS, (III) $1 \mathrm{mM} \mathrm{AgNP/CS,} \mathrm{(IV)} 2 \mathrm{mM} \mathrm{AgNP/CS}$, and (V) $4 \mathrm{mM} \mathrm{AgNP/CS}$, respectively.

have the tendency to agglomerate. Such agglomeration may serve as stress concentration sites, facilitating the crack propagation during tensile testing hence reducing the samples strain at break, see Figure 7.

The antibacterial performance of pure CS, plasma treated CS, and AgNP/CS films towards $S$. aureus and E. coli bacterial strains are shown in Figure 9. Pure CS and plasma treated CS films displayed no antibacterial activity, which is consistent with previous reports [62]. In contrast, bacteria inhibition zones were clearly seen for all the AgNP/CS films against both bacterial strains. For E.coli particularly, the size of the inhibition zones increases significantly with increasing Ag content. The presence of AgNPs can contribute to the strong antimicrobial effect by generating reactive oxygen species (ROS) [63,64]. The ROS species formed within the AgNP/CS films can diffuse / migrate to the sample surface, during swelling of the nanocomposite films. When in contact with the bacterial strains, the ROS could destabilize their plasma membrane potential and deplete the levels of intracellular adenosine triphosphate, resulting in death of bacterial cells [65]. In addition, the small amount of residual Ag ions (as evidenced in the XPS results, Table 1) can also partly contribute to the antibacterial effects due to their ability to interact with the bacterial cell envelope and cellular molecules $[29,66]$. It is also noticed that the inhibition zone size for E. coli is larger than that of $S$. aureus for all AgNP/CS films. This is because $S$. aureus are surrounded by a thick peptidoglycan based cell wall $[2,67]$, whereas the gram-negative $E$. coli cell wall comprises of a thin layer of negatively charged lipopolysaccharide, which is more prone to attack by antibacterial agents.

\section{Conclusion}

In conclusion, we have successfully demonstrated a facile approach for the synthesis of AgNPs loaded CS nanocomposites deploying atmospheric pressure microplasma liquid interaction. 

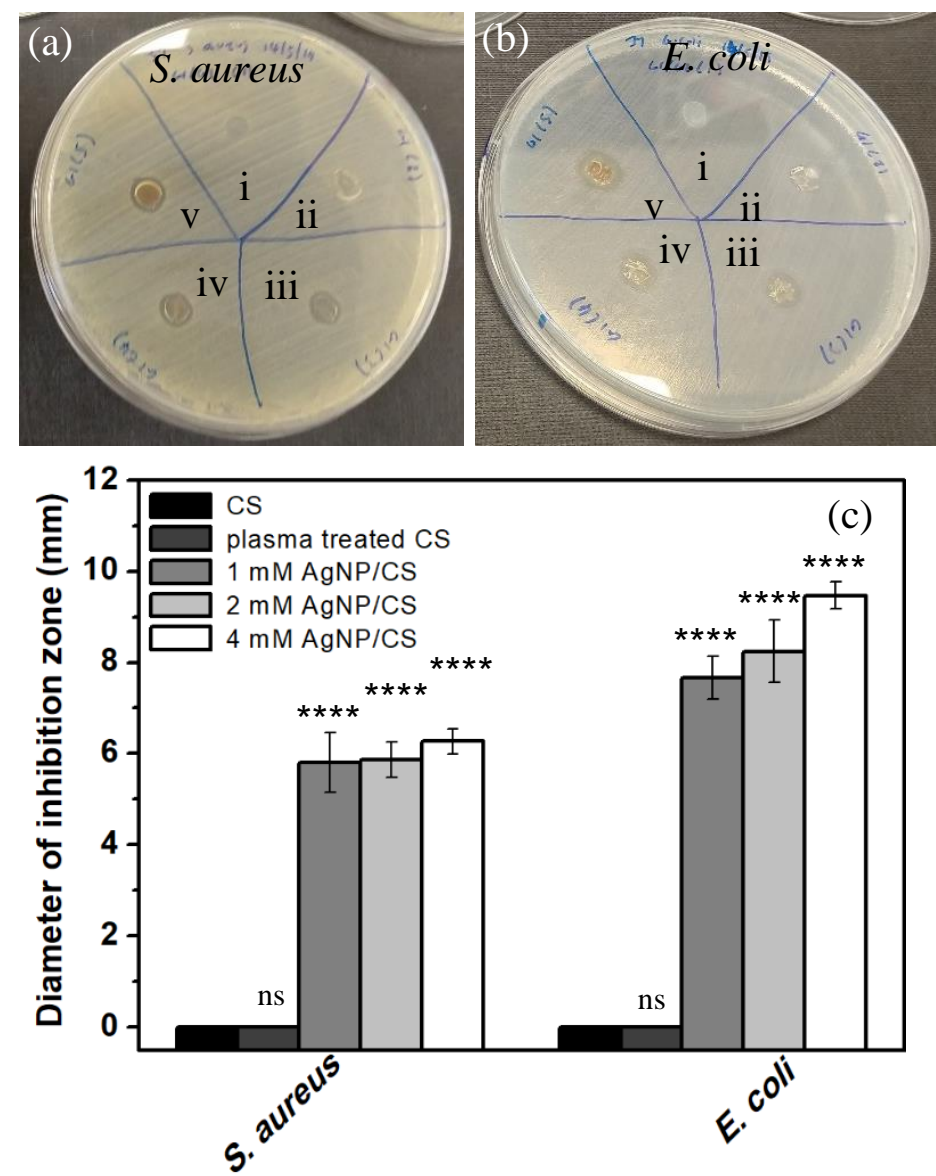

Figure 9. Antibacterial analysis using S. aureus and E.coli; (a) and (b) antibacterial performances of (i) CS, (ii) plasma treated CS, (iii) $1 \mathrm{mM} \mathrm{AgNP/CS}$, (iv) $2 \mathrm{mM} \mathrm{AgNP/CS}$, and (v) $4 \mathrm{mM} \mathrm{AgNP/CS}$ against S.aureus and E.coli bacterial strain, respectively; (c) corresponding average diameter of each inhibition zone. Data were presented as mean $\pm S$, $\mathrm{E}$, and $\mathrm{N}=5$. One way ANOVA followed by Dunnett's multiple comparisons test. **** $\mathrm{p}<0.0001$.

The unique process serves dual functions, i.e., in situ reduction of AgNP and tailoring the CS structure and properties, leading to nanocomposites with improved mechanical properties compared to pure CS. This shows the potential of the new approach for the rapid synthesis of functional nanocomposites with be-spoke properties. Our plasma synthesised AgNP/CS nanocomposites also demonstrates effective anti-microbial properties, which may enable them for a wide range of applications such as antibacterial coatings, would dressings and membranes for water sanitation, etc.

\section{Acknowledgements:}

The authors would like to acknowledge the Engineering and Physical Sciences Research Council (EPSRC) for funding support (EP/P00394X/1 and EP/M024938/1). Daye Sun thanks the China Scholarship Council (CSC) for the financial support. 


\section{References}

[1] F. Prestinaci, P. Pezzotti, A. Pantosti, Antimicrobial resistance: a global multifaceted phenomenon, Pathog. Glob. Health. (2015). doi:10.1179/2047773215Y.0000000030.

[2] S. Shrivastava, T. Bera, A. Roy, G. Singh, P. Ramachandrarao, D. Dash, Characterization of enhanced antibacterial effects of novel silver nanoparticles, Nanotechnology. (2007). doi:10.1088/0957-4484/18/22/225103.

[3] G. Franci, A. Falanga, S. Galdiero, L. Palomba, M. Rai, G. Morelli, M. Galdiero, Silver nanoparticles as potential antibacterial agents, Molecules. (2015). doi:10.3390/molecules20058856.

[4] J.F. Huang, Q.S. Shi, J. Feng, M.J. Chen, W.R. Li, L.Q. Li, Facile pyrolysis preparation of rosin-derived biochar for supporting silver nanoparticles with antibacterial activity, Compos. Sci. Technol. (2017). doi:10.1016/j.compscitech.2017.03.042.

[5] A.B.G. Lansdown, A pharmacological and toxicological profile of silver as an antimicrobial agent in medical devices, Adv. Pharmacol. Sci. (2010). doi:10.1155/2010/910686.

[6] E. Marsich, F. Bellomo, G. Turco, A. Travan, I. Donati, S. Paoletti, Nano-composite scaffolds for bone tissue engineering containing silver nanoparticles: Preparation, characterization and biological properties, J. Mater. Sci. Mater. Med. (2013). doi:10.1007/s10856-013-4923-4.

[7] S.K. Mishra, J.M.F. Ferreira, S. Kannan, Mechanically stable antimicrobial chitosanPVA-silver nanocomposite coatings deposited on titanium implants, Carbohydr. Polym. (2015). doi:10.1016/j.carbpol.2014.12.027.

[8] T. Maneerung, S. Tokura, R. Rujiravanit, Impregnation of silver nanoparticles into bacterial cellulose for antimicrobial wound dressing, Carbohydr. Polym. (2008). doi:10.1016/j.carbpol.2007.07.025.

[9] K. Shameli, M. Bin Ahmad, W. Md Zin Wan Yunus, N.A. Ibrahim, R.A. Rahman, M. Jokar, M. Darroudi, Silver/poly (lactic acid) nanocomposites: Preparation, characterization, and antibacterial activity, Int. J. Nanomedicine. (2010).

[10] S.S. Shankar, A. Rai, A. Ahmad, M. Sastry, Rapid synthesis of Au, Ag, and bimetallic Au core-Ag shell nanoparticles using Neem (Azadirachta indica) leaf broth, J. Colloid Interface Sci. (2004). doi:10.1016/j.jcis.2004.03.003.

[11] S.M. Li, N. Jia, M.G. Ma, Z. Zhang, Q.H. Liu, R.C. Sun, Cellulose-silver nanocomposites: Microwave-assisted synthesis, characterization, their thermal stability, and antimicrobial property, Carbohydr. Polym. (2011). doi:10.1016/j.carbpol.2011.04.060.

[12] G. Sahni, P. Gopinath, P. Jeevanandam, A novel thermal decomposition approach to synthesize hydroxyapatite-silver nanocomposites and their antibacterial action against GFP-expressing antibiotic resistant E. coli, Colloids Surfaces B Biointerfaces. (2013). doi:10.1016/j.colsurfb.2012.10.050.

[13] A. Nikiforov, X. Deng, Q. Xiong, U. Cvelbar, N. Degeyter, R. Morent, C. Leys, Nonthermal plasma technology for the development of antimicrobial surfaces: A review, J. Phys. D. Appl. Phys. (2016). doi:10.1088/0022-3727/49/20/204002.

[14] M. Gorjanc, V. Bukošek, M. Gorenšek, M. Mozetič, CF4 plasma and silver functionalized cotton, Text. Res. J. (2010). doi:10.1177/0040517510376268.

[15] N.K. Vu, A. Zille, F.R. Oliveira, N. Carneiro, A.P. Souto, Effect of particle size on silver nanoparticle deposition onto dielectric barrier discharge (DBD) plasma functionalized polyamide fabric, Plasma Process. Polym. (2013). doi:10.1002/ppap.201200089.

[16] E. Körner, M.H. Aguirre, G. Fortunato, A. Ritter, J. Rühe, D. Hegemann, Formation and distribution of silver nanoparticles in a functional plasma polymer matrix and related 
Ag+ release properties, Plasma Process. Polym. (2010). doi:10.1002/ppap.200900163.

[17] E. Körner, B. Hanselmann, P. Cierniak, D. Hegemann, Tailor-made silver release properties of silver-containing functional plasma polymer coatings adjusted through a macroscopic kinetics approach, in: Plasma Chem. Plasma Process., 2012. doi:10.1007/s11090-012-9362-3.

[18] M. Vaidulych, J. Hanuš, T. Steinhartová, O. Kylián, A. Choukourov, J. Beranová, I. Khalakhan, H. Biederman, Deposition of $\mathrm{Ag} / \mathrm{a}-\mathrm{C}: \mathrm{H}$ nanocomposite films with $\mathrm{Ag}$ surface enrichment, Plasma Process. Polym. (2017). doi:10.1002/ppap.201600256.

[19] M. Agarwala, T. Barman, D. Gogoi, B. Choudhury, A.R. Pal, R.N.S. Yadav, Highly effective antibiofilm coating of silver-polymer nanocomposite on polymeric medical devices deposited by one step plasma process, J. Biomed. Mater. Res. - Part B Appl. Biomater. (2014). doi:10.1002/jbm.b.33106.

[20] E. Sardella, P. Favia, R. Gristina, M. Nardulli, R. d'Agostino, Plasma-aided micro- and nanopatterning processes for biomedical applications, Plasma Process. Polym. (2006). doi:10.1002/ppap.200600041.

[21] P. Favia, M. Vulpio, R. Marino, R. D’Agostino, R.P. Mota, M. Catalano, Plasmadeposition of Ag-containing polyethyleneoxide-like coatings, Plasmas Polym. (2000). doi:10.1023/A:1009517408368.

[22] D. Mariotti, R.M. Sankaran, Microplasmas for nanomaterials synthesis, J. Phys. D. Appl. Phys. 43 (2010) 323001. doi:10.1088/0022-3727/43/32/323001.

[23] J. Patel, L. Němcová, P. Maguire, W.G. Graham, D. Mariotti, Synthesis of surfactantfree electrostatically stabilized gold nanoparticles by plasma-induced liquid chemistry, Nanotechnology. 24 (2013) 245604. doi:10.1088/0957-4484/24/24/245604.

[24] X.Z. Huang, X.X. Zhong, Y. Lu, Y.S. Li, a E. Rider, S. a Furman, K. Ostrikov, Plasmonic Ag nanoparticles via environment-benign atmospheric microplasma electrochemistry, Nanotechnology. $24 \quad$ (2013) 095604. doi:10.1088/09574484/24/9/095604.

[25] D. Sun, J.R. McLaughlan, L. Zhang, B.G. Falzon, D. Mariotti, P.D. Maguire, D. Sun, Atmospheric Pressure Plasma Synthesized Gold Nanoparticle/Carbon Nanotube Hybrids for Photo-thermal Conversion, Langmuir. (2019). doi:10.1021/acs.langmuir.8b03945.

[26] B. Gabriel, ce pte d M an us cri pt Ac ce pte d M us pt, Clin. Sci. (2012) 1-23.

[27] H. Nolan, D. Sun, B.G. Falzon, P. Maguire, D. Mariotti, L. Zhang, D. Sun, Thermoresponsive nanocomposites incorporating microplasma synthesized magnetic nanoparticles - Synthesis and potential applications, Plasma Process. Polym. (2019). doi:10.1002/ppap.201800128.

[28] R.C. Zhang, D. Sun, R. Zhang, W.F. Lin, M. Macias-Montero, J. Patel, S. Askari, C. McDonald, D. Mariotti, P. Maguire, Gold nanoparticle-polymer nanocomposites synthesized by room temperature atmospheric pressure plasma and their potential for fuel cell electrocatalytic application, Sci. Rep. (2017). doi:10.1038/srep46682.

[29] H. Nolan, D. Sun, B.G. Falzon, S. Chakrabarti, D.B. Padmanaba, P. Maguire, D. Mariotti, T. Yu, D. Jones, G. Andrews, D. Sun, Metal nanoparticle-hydrogel nanocomposites for biomedical applications - An atmospheric pressure plasma synthesis approach, Plasma Process. Polym. 15 (2018). doi:10.1002/ppap.201800112.

[30] R. Jayakumar, D. Menon, K. Manzoor, S. V. Nair, H. Tamura, Biomedical applications of chitin and chitosan based nanomaterials - A short review, Carbohydr. Polym. (2010). doi:10.1016/j.carbpol.2010.04.074.

[31] K. Xu, C. Liu, K. Kang, Z. Zheng, S. Wang, Z. Tang, W. Yang, Isolation of nanocrystalline cellulose from rice straw and preparation of its biocomposites with chitosan: Physicochemical characterization and evaluation of interfacial compatibility, 
Compos. Sci. Technol. (2018). doi:10.1016/j.compscitech.2017.10.022.

[32] A. Barra, N.M. Ferreira, M.A. Martins, O. Lazar, A. Pantazi, A.A. Jderu, S.M. Neumayer, B.J. Rodriguez, M. Enăchescu, P. Ferreira, C. Nunes, Eco-friendly preparation of electrically conductive chitosan - reduced graphene oxide flexible bionanocomposites for food packaging and biological applications, Compos. Sci. Technol. (2019). doi:10.1016/j.compscitech.2019.01.027.

[33] A.M. Salaberría, R. Teruel-Juanes, J.D. Badia, S.C.M. Fernandes, V. Sáenz de JuanoArbona, J. Labidi, A. Ribes-Greus, Influence of chitin nanocrystals on the dielectric behaviour and conductivity of chitosan-based bionanocomposites, Compos. Sci. Technol. (2018). doi:10.1016/j.compscitech.2018.08.019.

[34] E. Luna-Hernández, M.E. Cruz-Soto, F. Padilla-Vaca, R.A. Mauricio-Sánchez, D. Ramirez-Wong, R. Muñoz, L. Granados-López, L.R. Ovalle-Flores, J.L. MenchacaArredondo, A. Hernández-Rangel, E. Prokhorov, J.L. García-Rivas, B.L. EspañaSánchez, G. Luna-Bárcenas, Combined antibacterial/tissue regeneration response in thermal burns promoted by functional chitosan/silver nanocomposites, Int. J. Biol. Macromol. (2017). doi:10.1016/j.ijbiomac.2017.07.159.

[35] H. Ye, J. Cheng, K. Yu, In situ reduction of silver nanoparticles by gelatin to obtain porous silver nanoparticle/chitosan composites with enhanced antimicrobial and woundhealing activity, Int. J. Biol. Macromol. (2019). doi:10.1016/j.ijbiomac.2018.10.056.

[36] M. Yadollahi, S. Farhoudian, H. Namazi, One-pot synthesis of antibacterial chitosan/silver bio-nanocomposite hydrogel beads as drug delivery systems, Int. J. Biol. Macromol. (2015). doi:10.1016/j.ijbiomac.2015.04.032.

[37] Q. Li, F. Lu, G. Zhou, K. Yu, B. Lu, Y. Xiao, F. Dai, D. Wu, G. Lan, Silver Inlaid with Gold Nanoparticle/Chitosan Wound Dressing Enhances Antibacterial Activity and Porosity, and Promotes Wound Healing, Biomacromolecules. (2017). doi:10.1021/acs.biomac.7b01180.

[38] ASTM International, Standard Test Method for Tensile Properties of Thin Plastic Sheeting, ASTM Stand. (2012). doi:10.1520/D0882-12.2.

[39] Clinical and Laboratory Standards Institute (CLSI), Performance standards for antimicrobial disk susceptibility tests M02-A11, 2012. doi:M02-A11.

[40] S. Agnihotri, S. Mukherji, S. Mukherji, Size-controlled silver nanoparticles synthesized over the range 5-100 $\mathrm{nm}$ using the same protocol and their antibacterial efficacy, RSC Adv. (2014). doi:10.1039/c3ra44507k.

[41] I. Fratoddi, R. Matassa, L. Fontana, I. Venditti, G. Familiari, C. Battocchio, E. Magnano, S. Nappini, G. Leahu, A. Belardini, R. Li Voti, C. Sibilia, Electronic Properties of a Functionalized Noble Metal Nanoparticles Covalent Network, J. Phys. Chem. C. (2017). doi:10.1021/acs.jpcc.7b07176.

[42] R. Wang, S. Zuo, W. Zhu, S. Wu, W. Nian, J. Zhang, J. Fang, Microplasma-assisted growth of colloidal silver nanoparticles for enhanced antibacterial activity, Plasma Process. Polym. (2014). doi:10.1002/ppap.201300038.

[43] V.S.S.K. Kondeti, U. Gangal, S. Yatom, P.J. Bruggeman, Ag + reduction and silver nanoparticle synthesis at the plasma-liquid interface by an RF driven atmospheric pressure plasma jet: Mechanisms and the effect of surfactant, J. Vac. Sci. Technol. A Vacuum, Surfaces, Film. (2017). doi:10.1116/1.4995374.

[44] Y.L. Thong, O.H. Chin, B.H. Ong, N.M. Huang, Synthesis of silver nanoparticles prepared in aqueous solutions using helium dc microplasma jet, in: Jpn. J. Appl. Phys., 2016. doi:10.7567/JJAP.55.01AE19.

[45] D. Mariotti, J. Patel, V. ??vr??ek, P. Maguire, Plasma-liquid interactions at atmospheric pressure for nanomaterials synthesis and surface engineering, Plasma Process. Polym. 9 (2012) 1074-1085. doi:10.1002/ppap.201200007. 
[46] P.J. Bruggeman, M.J. Kushner, B.R. Locke, J.G.E. Gardeniers, W.G. Graham, D.B. Graves, R.C.H.M. Hofman-Caris, D. Maric, J.P. Reid, E. Ceriani, D. Fernandez Rivas, J.E. Foster, S.C. Garrick, Y. Gorbanev, S. Hamaguchi, F. Iza, H. Jablonowski, E. Klimova, J. Kolb, F. Krcma, P. Lukes, Z. MacHala, I. Marinov, D. Mariotti, S. Mededovic Thagard, D. Minakata, E.C. Neyts, J. Pawlat, Z.L. Petrovic, R. Pflieger, S. Reuter, D.C. Schram, S. Schröter, M. Shiraiwa, B. Tarabová, P.A. Tsai, J.R.R. Verlet, T. Von Woedtke, K.R. Wilson, K. Yasui, G. Zvereva, Plasma-liquid interactions: A review and roadmap, Plasma Sources Sci. Technol. 25 (2016). doi:10.1088/09630252/25/5/053002.

[47] M. Rehan, A. Barhoum, G. Van Assche, A. Dufresne, L. Gätjen, R. Wilken, Towards multifunctional cellulosic fabric: UV photo-reduction and in-situ synthesis of silver nanoparticles into cellulose fabrics, Int. J. Biol. Macromol. (2017). doi:10.1016/j.ijbiomac.2017.02.058.

[48] J. Brugnerotto, J. Lizardi, F.M. Goycoolea, W. Argüelles-Monal, J. Desbrières, M. Rinaudo, An infrared investigation in relation with chitin and chitosan characterization, Polymer (Guildf). (2001). doi:10.1016/S0032-3861(00)00713-8.

[49] A.D. Kurdekar, L.A.A. Chunduri, S.M. Chelli, M.K. Haleyurgirisetty, E.P. Bulagonda, J. Zheng, I.K. Hewlett, V. Kamisetti, Fluorescent silver nanoparticle based highly sensitive immunoassay for early detection of HIV infection, RSC Adv. (2017). doi:10.1039/c6ra28737a.

[50] P. Li, X. Zhang, R. Xu, W. Wang, X. Liu, K.W.K. Yeung, P.K. Chu, Electrochemically deposited chitosan/Ag complex coatings on biomedical NiTi alloy for antibacterial application, Surf. Coatings Technol. (2013). doi:10.1016/j.surfcoat.2013.05.037.

[51] S. Saber-Samandari, O. Yilmaz, E. Yilmaz, Photoinduced graft copolymerization onto chitosan under heterogeneous conditions, J. Macromol. Sci. Part A Pure Appl. Chem. (2012). doi:10.1080/10601325.2012.687970.

[52] L.S. Guinesi, É.T.G. Cavalheiro, The use of DSC curves to determine the acetylation degree of chitin/chitosan samples, Thermochim. Acta. (2006). doi:10.1016/j.tca.2006.03.003.

[53] M. Lavorgna, I. Attianese, G.G. Buonocore, A. Conte, M.A. Del Nobile, F. Tescione, E. Amendola, MMT-supported Ag nanoparticles for chitosan nanocomposites: Structural properties and antibacterial activity, Carbohydr. Polym. (2014). doi:10.1016/j.carbpol.2013.11.026.

[54] D. Zhang, S. Yang, Y. Chen, S. Liu, H. Zhao, J. Gu, 60 Co $\gamma$-ray irradiation crosslinking of chitosan/graphene oxide composite film: Swelling, thermal stability, mechanical, and antibacterial properties, Polymers (Basel). (2018). doi:10.3390/polym10030294.

[55] R. Molina, P. Jovancic, S. Vilchez, T. Tzanov, C. Solans, In situ chitosan gelation initiated by atmospheric plasma treatment, Carbohydr. Polym. (2014). doi:10.1016/j.carbpol.2013.12.084.

[56] K.L.B. Chang, M.C. Tai, F.H. Cheng, Kinetics and products of the degradation of chitosan by hydrogen peroxide, J. Agric. Food Chem. (2001). doi:10.1021/jf001469g.

[57] Y. Guan, J. Chen, X. Qi, G. Chen, F. Peng, R. Sun, Fabrication of Biopolymer Hydrogel Containing Ag Nanoparticles for Antibacterial Property, Ind. Eng. Chem. Res. (2015). doi:10.1021/acs.iecr.5b01532.

[58] K. Balani, V. Verma, A. Agarwal, R. Narayan, Physical, Thermal, and Mechanical Properties of Polymers, in: Biosurfaces, 2015. doi:10.1002/9781118950623.app1.

[59] An introduction to hydrogen bonding, Choice Rev. Online. (1998). doi:10.5860/choice.35-3309.

[60] P.H. Chen, T.Y. Kuo, F.H. Liu, Y.H. Hwang, M.H. Ho, D.M. Wang, J.Y. Lai, H.J. Hsieh, Use of dicarboxylic acids to improve and diversify the material properties of 
porous chitosan membranes, J. Agric. Food Chem. (2008). doi:10.1021/jf801081e.

[61] K. Shahzadi, L. Wu, X. Ge, F. Zhao, H. Li, S. Pang, Y. Jiang, J. Guan, X. Mu, Preparation and characterization of bio-based hybrid film containing chitosan and silver nanowires, Carbohydr. Polym. (2016). doi:10.1016/j.carbpol.2015.11.012.

[62] J.R. Rodríguez-Núñez, J. López-Cervantes, D.I. Sánchez-Machado, B. Ramírez-Wong, P. Torres-Chavez, M.O. Cortez-Rocha, Antimicrobial activity of chitosan-based films against Salmonella typhimurium and Staphylococcus aureus, Int. J. Food Sci. Technol. (2012). doi:10.1111/j.1365-2621.2012.03079.x.

[63] W. Salem, D.R. Leitner, F.G. Zingl, G. Schratter, R. Prassl, W. Goessler, J. Reidl, S. Schild, Antibacterial activity of silver and zinc nanoparticles against Vibrio cholerae and enterotoxic Escherichia coli, Int. J. Med. Microbiol. (2015). doi:10.1016/j.ijmm.2014.11.005.

[64] H. Le Pape, F. Solano-Serena, P. Contini, C. Devillers, A. Maftah, P. Leprat, Involvement of reactive oxygen species in the bactericidal activity of activated carbon fibre supporting silver: Bactericidal activity of $\mathrm{ACF}(\mathrm{Ag})$ mediated by ROS, J. Inorg. Biochem. (2004). doi:10.1016/j.jinorgbio.2004.02.025.

[65] K. Varaprasad, Y. Murali Mohan, S. Ravindra, N. Narayana Reddy, K. Vimala, K. Monika, B. Sreedhar, K. Mohana Raju, Hydrogel-silver nanoparticle composites: A new generation of antimicrobials, J. Appl. Polym. Sci. (2010). doi:10.1002/app.31249.

[66] A. Kędziora, M. Speruda, E. Krzyżewska, J. Rybka, A. Łukowiak, G. BuglaPłoskońska, Similarities and differences between silver ions and silver in nanoforms as antibacterial agents, Int. J. Mol. Sci. (2018). doi:10.3390/ijms19020444.

[67] M. Qasim, N. Udomluck, J. Chang, H. Park, K. Kim, Antimicrobial activity of silver nanoparticles encapsulated in poly-N-isopropylacrylamide-based polymeric nanoparticles, Int. J. Nanomedicine. (2018). doi:10.2147/IJN.S153485. 